\title{
Conteúdos Curriculares em Jogos Digitais Educacionais: Desafios de um Processo Participativo
}

\author{
Dyego C. S. de Morais ${ }^{1}$, Taciana Pontual da R. Falcão ${ }^{2}$, Glaucileide da S. Oliveira ${ }^{1}$, \\ Flávia M. A. Peres ${ }^{1}$ \\ ${ }^{1}$ Departamento de Educação - Universidade Federal Rural de Pernambuco (UFRPE) \\ Recife, PE - Brasil \\ ${ }^{2}$ Departamento de Estatística e Informática - Universidade Federal Rural de \\ Pernambuco (UFRPE) - Recife, PE - Brasil
}

moraisdcs@gmail.com, taciana.pontual@gmail.com,
glauci_ufrpe@hotmail.com, peres.flavia@gmail.com

\begin{abstract}
Based on a socio-interactionist approach, the DEMULTS project is organized as a community of practice in the school context, in which students interact with experts to develop digital educational games within a participatory process. In this process, students learn about design, programming, and about the contents related to knowledge areas addressed by each game. The appropriation of these contents, however, and their integration to the games' narrative, presents challenges related to the fun of the game, time available for ideation, experts' engagement, and students' autonomy to seek such knowledge.
\end{abstract}

Resumo. Baseado em uma abordagem teórica sócio-interacionista, o projeto DEMULTS é organizado como uma comunidade de prática no contexto escolar, na qual educandos interagem com experts para desenvolver jogos digitais educacionais em um processo participativo. Nesse processo, os educandos aprendem sobre design, programação, e sobre os conteúdos das áreas de conhecimento abordadas em cada jogo. A apropriação destes conteúdos, no entanto, e sua integração à narrativa dos jogos, apresenta desafios relacionados à ludicidade do jogo, o tempo disponível para ideação, $o$ engajamento dos experts e a autonomia dos estudantes para buscar construir esse conhecimento.

\section{Introdução}

Cada vez menos os estudantes se adequam ao sistema educacional que está posto, dada a incompatibilidade entre suas características de aprendizagem e os métodos convencionais aplicados em muitas escolas [Prensky 2001]. Frente a essas divergências, Prensky (2010) aponta a necessidade da criação de abordagens para educação mais adequadas a esta geração, como por exemplo a utilização de jogos digitais, que podem ser vistos como uma linguagem com a qual os educandos estão familiarizados. 
Há relatos de resultados positivos em relação ao uso de jogos digitais como ferramentas educacionais de revisão sobre conteúdos ou como motivação para primeiro contato com novos conteúdos [Kafai 2006, Halverson et al. 2006]. Esse tipo de aplicação de jogos no contexto escolar pode ser classificado como instrucionista, segundo teoria de Papert e Harel (1991). Outros autores focam não apenas no uso, mas no desenvolvimento de jogos digitais por educandos em contexto escolar [Marinho et al. 2011]. Essa vertente enquadra-se no que Papert e Harel (1991) classificam como teoria construcionista da aprendizagem. Tal abordagem possibilita novas diretrizes pedagógicas para a aprendizagem não só de conceitos técnicos de programação e design, mas também de conteúdos curriculares que podem ser integrados aos jogos, seja pela narrativa, seja pela jogabilidade [Robertson e Howells 2008].

Entretanto, integrar mecânicas e narrativas divertidas e conceitos de disciplinas curriculares em um jogo tende a gerar grandes desafios para os educandos. Tais desafios são percebidos nos ciclos de intervenção do DEMULTS (Desenvolvimento Educacional de Multimídias Sustentáveis), projeto de pesquisa que aplica metodologias participativas em uma escola pública de nível médio para que os educandos desenvolvam jogos digitais educacionais em conjunto com especialistas em design, em programação e nos conteúdos curriculares específicos abordados em cada jogo. No DEMULTS, investigam-se aprendizagens emergentes de comunidades de prática [Lave e Wenger 1991] de desenvolvimento de jogos, através das situações discursivas no ambiente escolar, provendo modelos inovadores à aprendizagem formal e tornando-a mais motivadora para a internalização de competências e conceitos científicos.

Este artigo apresenta reflexões no contexto do DEMULTS, focadas nos desafios da apropriação dos conteúdos curriculares e sua integração aos jogos desenvolvidos pelos educandos. Na seção seguinte, detalhamos a metodologia seguida pelo DEMULTS e o arcabouço teórico em que ela se baseia. A seção 3 apresenta os jogos produzidos no projeto, e as reflexões decorrentes das peculiaridades de cada ciclo. A seção 4 apresenta uma discussão dos resultados e indica direções futuras.

\section{Metodologia e Arcabouço Teórico do DEMULTS}

O DEMULTS fundamenta-se em uma abordagem sócio-interacionista em psicologia e educação [Leontiev 2004, Saviani 2003], que destaca a importância das interações sociais para o desenvolvimento psíquico, e o papel da escola como fundamental para que os sujeitos se apropriem de conhecimentos científicos, artísticos, filosóficos e corporais em suas formas mais avançadas. O projeto estrutura-se como uma Comunidade de Prática - CP (grupo de pessoas que visa desenvolver habilidades em torno de um interesse em comum, compartilhando práticas, negociando significados, identidades e culturas, formando assim um sistema de aprendizagem social [Wenger 2000]) em que experts (equipe do DEMULTS e professores da escola) e iniciantes (educandos da escola) interagem em atividades que compõem o processo de desenvolvimento de jogos digitais educacionais. As situações discursivas nos contextos de ação na $\mathrm{CP}$ podem promover um modelo participativo que inverte a lógica hierárquica de estruturação das atividades escolares. Os experts medeiam a internalização dos conceitos científicos através do diálogo, e com o auxílio de textos e 
desenhos, com o objetivo de solucionarem os conflitos junto com os iniciantes. Tal característica se aproxima ao conceito de Zona de Desenvolvimento Proximal (ZDP) [Vygotsky 1991], que enfatiza a distância entre o nível de desenvolvimento real, referente ao que o sujeito consegue realizar sozinho, independente da ajuda de outros, e o nível de desenvolvimento potencial, referente ao que só consegue resolver com a ajuda de experts ou companheiros mais autônomos.

Para viabilizar o desenvolvimento dos jogos pelos educandos (com o auxílio dos experts) na CP, são usadas as técnicas de Design Participativo (DP) [Bødker et al. 1995; Ehn 1991] e Programação pelo Usuário Final (PUF) [Lieberman 2006]. Na prática do DP, as pessoas que são influenciadas pelo que está sendo projetado participam ativamente de suas definições e negociam múltiplos aspectos de uma mesma situação. Uma vez que os jogos digitais projetados se destinam a educandos de Ensino Médio e os desenvolvedores são educandos do Ensino Médio, conforme ideias advindas do DP, há experiência da vivência real da situação pelos participantes, que podem contribuir com propriedade, enfatizando aspectos cruciais. Em relação à PUF, destaca-se a possibilidade de um usuário final alterar um software em diferentes níveis para que satisfaça suas necessidades [Morch 1997]. Para prover suporte a PUF, as atividades de programação são realizadas no ambiente de programação visual Stencyl ${ }^{1}$, que possibilita usuários não-programadores desenvolverem jogos, reduzindo a preocupação com a sintaxe da linguagem de programação [Maloney et al. 2010]. As atividades de design são realizadas em vários softwares, como o Inkscape ${ }^{2}$, recentemente o mais empregado.

O DEMULTS é realizado em uma escola pública desde 2012, em ciclos de aproximadamente um ano, idealmente iniciando-se e encerrando-se junto com o semestre escolar (embora nem sempre seja possível, devido a fatores do contexto e diferenças no ritmo dos grupos). Em cada ciclo, um grupo de aproximadamente 30 educandos das turmas de primeiro ou segundo ano do ensino médio é selecionado para participar do projeto. Os educandos podem assumir os papéis de designers ou programadores, podendo também haver subgrupos de acordo com as disciplinas escolares que serão abordadas nos jogos (se houver mais de uma no mesmo ciclo).

Cada ciclo do DEMULTS se inicia com uma etapa curta de aulas e workshops para familiarizar os educandos com as ferramentas a serem utilizadas; conceitos básicos de game design, ilustração e programação; e avaliação de jogos educacionais. Em seguida, ocorre a etapa de ideação, apoiada por técnicas de tempestade de ideias (brainstorm) e mapas mentais, em que os educandos geram e selecionam democraticamente ideias para a narrativa e mecânica dos jogos a serem desenvolvidos. As ideias escolhidas são representadas por meio de Game Design Document - GDD (no primeiro ciclo) e storyboards (nos ciclos seguintes), artefatos que servem de referência e guia para o desenvolvimento dos jogos [Morais et al. 2015], podendo ser constantemente adaptadas e estendidas durante o processo.

A etapa de produção ocorre por meio de atividades práticas de ilustração e programação, realizadas pelos educandos com o apoio constante dos experts em

\footnotetext{
${ }^{1}$ www.stencyl.com

${ }^{2}$ https://inkscape.org/
} 
Computação, Design, e áreas de conhecimento específicas de cada ciclo (de acordo com as disciplinas curriculares a serem integradas aos jogos). Ao final da produção, os jogos passam por uma etapa de testes conduzida pelos próprios educandos com colegas da escola que não participaram do projeto.

A pesquisa no DEMULTS orienta-se pela etnografia, com coleta de dados através de observações participantes, aplicação de questionários, entrevistas, registros de interações virtuais e presenciais, fotografias contextualizadas e videografias de momentos pertinentes ao processo. Os dados são coletados e analisados qualitativamente ao longo dos ciclos pelos pesquisadores do projeto, alunos de pósgraduação e de iniciação científica. A quantidade de dados gerada pelo DEMULTS é vasta e as unidades de análise podem ter focos e objetivos específicos, conforme visto nos trabalhos de Capezzera e Peres (2014), que focou no processo de ensinoaprendizagem, Morais et al. (2015), que focou nos artefatos mediadores, e Peres e Oliveira (2013), que focou na renovação de práticas educacionais por meio da inserção de jogos digitais no contexto escolar. Tais trabalhos possuem foco no primeiro ciclo do DEMULTS. Neste artigo, aborda-se os 3 ciclos do DEMULTS focando na seguinte unidade de análise: integração de conteúdos curriculares em jogos digitais.

\section{Jogos Produzidos e Contribuições à Aprendizagem}

Três ciclos do DEMULTS foram realizados com educandos e educandas do primeiro ano do Ensino Médio na mesma escola pública, integrando conteúdos das disciplinas: Biologia e História (2012); Química (2013); Português e Matemática (2015). As peculiaridades de cada um são discutidas a seguir.

\subsection{Ciclo 1: Biologia e História}

No primeiro ciclo, foram desenvolvidos os jogos "Vírion" (o vírus da dengue em sua saga para fragilizar o sistema imune do corpo humano) e "Abydos" (sobre a história de Osíris, deus da mitologia egípcia associado à vegetação e responsável pelo julgamento dos mortos). A escolha das disciplinas foi de acordo com o campo de atuação dos experts então integrantes do DEMULTS (uma licencianda em Biologia e uma em História). Compunham também a equipe dois licenciandos em computação e uma bacharelanda em sistema de informação. Todos trabalhavam com os educandos em design gráfico, game design, programação e no suporte didático dos conteúdos curriculares. Não houve participação ativa de professores da escola. O ciclo durou 18 meses, o que possibilitou um tempo maior para ideação dos jogos, sendo portanto o ciclo com mais resultados positivos de integração de conteúdos nos jogos.

Ao longo do processo de integração dos conteúdos curriculares aos jogos, os educandos demonstraram constante engajamento. A análise das interações presenciais e a distância mostrou diversas situações voltadas à discussão dos conteúdos de cada jogo. As postagens na rede social, por exemplo, contêm dúvidas acerca dos conceitos e pertinência de determinados conteúdos perante as narrativas dos jogos, evidenciando interações entre educandos e destes com experts, a partir de propostas e reflexões que emergem de suas pesquisas autônomas.

A criação do personagem Vírion, para o jogo de Biologia, ilustra bem a 
mediação de conceitos pelo expert. Inicialmente, Vírion foi criado por uma educanda, a partir de suas pesquisas pessoais sobre as características morfofisiológicas dos vírus. Porém, o personagem era uma representação genérica de vírus que não se enquadrava na narrativa do jogo, que tratava especificamente do vírus da dengue. Após diversos momentos de diálogo entre a educanda encarregada da tarefa de design e a expert em Biologia, observou-se a necessidade de mudar a estrutura de Vírion para que este obtivesse duas proteínas ligantes, o que o permitia ser destruído pelo sistema imunológico do corpo, quando conectado a um anticorpo, ou atacar e matar leucócitos, quando ligado a um destes. Na Figura 1 pode-se observar a evolução do Vírion ao longo do processo de desenvolvimento.

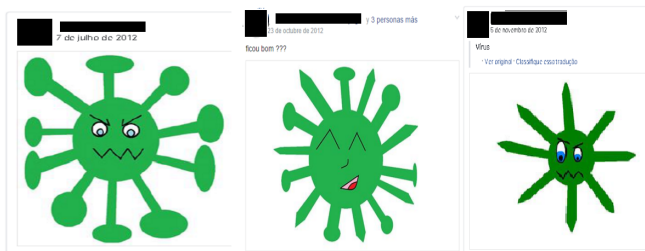

Figura 1. A evolução do personagem Vírion.

Momentos semelhantes de interação entre educandos e experts ocorreram também para o grupo de trabalho de História. Quando os educandos desenhavam o cenário e houve um anacronismo, percebido pela expert de História, onde um monumento que eles introduziram em uma cena não fazia parte do recorte espaçotemporal abordado no jogo. Ao notar o equívoco dos educandos, a expert procurou organizar as ideias trazidas por eles no tempo e espaço apropriados, de acordo com os dados históricos [Capezzera 2014].

\subsection{Ciclo 2: Química}

No segundo ciclo, a escolha da disciplina de Química se deu porque uma das mudanças propostas, em relação ao primeiro ciclo, era a inclusão efetiva da professora da disciplina como expert no processo de desenvolvimento do jogo. A professora de Química da escola demonstrou interesse no DEMULTS e assumiu a voz de expert no conteúdo curricular do jogo digital educacional. Além dela, a equipe de experts era composta por: três licenciandos em Computação, que não concluíram o ciclo devido a outras ocupações, e a mesma licencianda em História do ciclo 1, que permaneceu no projeto e guiou o processo de design participativo do jogo. Ao longo do processo a professora de Química afastou-se em licença maternidade, reduzindo sua atuação apenas ao grupo da rede social online. Ainda assim, as interações ocorridas nos momentos em que a expert estava ativa evidenciam uma forte influência relacionada ao conteúdo, no tratamento dos conceitos de Química que seriam trabalhados no jogo.

A definição do tema e das características do jogo durou vários encontros. Notouse que os educandos voluntariamente pesquisaram sobre conteúdos de Química para integrá-los ao jogo e diversas opções de jogos foram postadas no grupo da rede social. A professora discutiu sobre cada ideia inicialmente proposta e foi ajustando os conceitos científicos de Química trazidos pelos alunos em seus esboços do jogo (drafts), aproveitando as informações já internalizadas por eles e dando o suporte nos momentos 
VI Congresso Brasileiro de Informática na Educação (CBIE 2017)

Anais do XXIII Workshop de Informática na Escola (WIE 2017)

em que os educandos apresentavam dificuldade em abordar determinados conceitos. Isso também ocorreu entre os educandos: os que tinham mais domínio sobre a disciplina tentaram colaborar com aqueles com um nível real mais elementar para os conceitos de Química, no espaço simbólico da ZDP. Em diversos momentos seguintes, os alunos resgatavam as explicações da professora, evidenciando internalização conceitual. Democraticamente, foi escolhida uma opção para o jogo, que abordaria ligações covalentes e iônicas, assunto com o qual a maioria dos educandos se identificava.

Decorrente da participação da professora, observou-se um tema específico nas formações discursivas das interações, que não apareceu no ciclo 1, e relaciona-se com uma preocupação didática no tratamento conceitual, enfatizando a importância de relacionar os conceitos de Química com o cotidiano dos educandos, conforme fala da professora na rede social:

"Na verdade, a maioria das substâncias que conhecemos são resultados de ligações químicas. Os ácidos, os compostos orgânicos - açúcares, gasolina, medicamentos - são formados de ligações covalentes. Por outro lado, os sais e as bases - em especial os minerais - são compostos iônicos, ou seja, formados de ligações iônicas. O grande problema é que os livros fragmentam essas informações. Uma melhoria do jogo é, após as ligações formadas, dar oportunidade aos alunos de descobrir onde encontrar cada produto formado e mostrar que o jogo é uma forma diferente de apresentar as reações químicas. Qualquer dúvida estou sempre por aqui."

Um dos educandos-programadores deste ciclo destacou-se por sempre buscar novas possibilidades de mecânicas para o jogo, como percebido em suas postagens na rede social: "Aqui está o novo jogo que eu fiz, ele não tem nenhuma relação com química, mas de repente, poderia ser feita uma adaptação, onde a moeda de ouro seria um elemento químico puro que não pode ser atingido por contaminantes, ou algo do tipo... eu coloquei um pouco mais de dificuldade nesse, e as vezes acho q devia tar mais difícil kkk (sic.)". Percebeu-se que o educando tem consciência do objetivo educacional para o tratamento de conceitos de química, porém destaca a diversão como fundamental ao jogo,, pois quando perguntado o porquê de ter feito esse jogo mais difícil e como o usuário se sentiria, ele respondeu: "Acho que ele sente-se desafiado e cada vez que ele perde tem vontade de melhorar seus pontos, assim como no flappy bird (sic.)".

Os educandos refletiram, durante o processo, sobre quais aspectos um jogo deveria ter para cumprir suas funções educacionais e de diversão ao mesmo tempo. Para isso, a professora e os outros experts avaliaram jogos digitais de Química em conjunto com os educandos. Houve muitas críticas diante da monotonia de alguns jogos que se preocupavam com o conteúdo, mas não tinham uma jogabilidade que atraísse ou divertisse os jogadores; e de jogos que tratavam o assunto de Química de forma instrucionista, limitando-se a checar se o usuário havia memorizado informações externas ao jogo (como os elementos da tabela periódica, por exemplo) sem fazer os jogadores refletirem sobre os conceitos e situações da disciplina no cotidiano. Uma educanda, por exemplo, comentou no grupo da rede social sobre um jogo divulgado por uma expert: "não gostei muito, acredito que o jogador não tenha aprendido os princípios da química e suas utilidades, ficou vago". 
VI Congresso Brasileiro de Informática na Educação (CBIE 2017)

Anais do XXIII Workshop de Informática na Escola (WIE 2017)

\subsection{Ciclo 3: Português e Matemática}

Em 2015, as disciplinas foram escolhidas de acordo com interesses comuns das parcerias internacionais recém firmadas com universidades no Chile e na Colômbia. Optou-se então pelas áreas de Linguagem - gêneros textuais (Português, no Brasil, e Espanhol, nos outros dois países) e Matemática - geometria, com vistas a realizar estudos comparativos entre os respectivos contextos. Assim, compuseram a equipe de experts do projeto estudantes de licenciatura em: Matemática, Letras e Computação; além de dois voluntários da área de Design Gráfico, recém-concluintes de um curso técnico de Design de Jogos Digitais. Apesar de tentativas de articulação no início do ciclo, a participação de professores da escola não se concretizou.

Duas grandes dificuldades marcaram esse ciclo: o nível de desenvolvimento real dos educandos sobre os conteúdos curriculares estar muito elementar, embora já fossem conteúdos vistos nas aulas regulares, e isso refletir-se em dificuldades na construção de espaços simbólicos intersubjetivos que promovessem aprendizagem, com muitas ações dos experts no sentido de fornecerem mais explicações e encorajarem os educandos a fazerem suas próprias pesquisas sobre os assuntos; e os educandos idealizarem jogos que integrassem os conteúdos escolhidos e ainda assim fossem percebidos por eles próprios como divertidos. A falta de conhecimento sobre os conteúdos e a dificuldade em pesquisar e aprender criaram um entrave na fase de ideação, pois os educandos não conseguiam criar os storyboards com uma narrativa que contemplasse os conteúdos. Isso retardou o processo de ideação e gerou desmotivação nos educandos, ansiosos por começar a desenvolver os jogos de fato. Consequentemente, o desenvolvimento foi caminhando em paralelo à ideação até o final do processo.

Inicialmente, o grupo de Português propôs fases de mecânica e narrativa complexas, porém sem envolver qualquer conteúdo curricular. Ao longo dos encontros, houve dificuldades na comunicação do expert de Português com os educandos em discussões acerca do conteúdo de gêneros textuais, devido à linguagem rebuscada usada. Além disso, o expert disponibilizou documentos com alguns conceitos a serem estudados pelos educandos, mas estes não se sentiram motivados a consultá-los. Perto do final do ciclo, as interações foram intensificadas pelo expert visto que o grupo ainda não havia conseguido desenvolver uma narrativa focada no tema escolhido (estrutura de sonetos). Os educandos demonstraram grandes dificuldades para apropriarem-se e expandirem as sugestões do expert, apresentando muita dependência das ideias dele. Somente com a proximidade do prazo final e as repetidas conversas sobre o conteúdo, os educandos mostraram-se mais participativos nas discussões. Finalmente, o grupo convergiu para uma narrativa compreendida por todos, que incluiu as regras de formação de sonetos em formato de desafios lógicos. A criação desses desafios exigiu que os educandos aprendessem sobre a estrutura de sonetos, visto que a mecânica do jogo está intimamente interligada ao seu conteúdo.

O grupo de Matemática inicialmente propôs questões muito básicas relacionadas a figuras geométricas, no nível real que os aproximava dos conhecimentos mais elementares aprendidos no ensino fundamental. O expert precisou explicar a necessidade de contemplar conteúdos de ensino médio, dado o público-alvo do jogo. $\mathrm{Na}$ concepção do DEMULTS, destaca-se que essa necessidade também corresponde ao 
objetivo de proporcionar aos educandos a aprendizagem dos conteúdos curriculares por meio do desenvolvimento do jogo. Em colaboração com o expert, a primeira narrativa criada pelo grupo de Matemática (Figura 2, à esquerda) foi:

A batata vai fugir do cozinheiro e ela está na mesa e irá saltar para a pia com o auxílio de uma ratoeira, mas isso só se dará de forma correta se o jogador colocar a ratoeira de forma que o ângulo do salto seja o ângulo cujo seno é 1/2. Depois de saltar, a batata terá que atravessar a pia e para isso terá que usar uma colher cujo tamanho é igual à diagonal da pia, para que a batata atravesse por cima da colher, e depois disso para ir mais rápido se esconder do cozinheiro irá entrar em um copo, mas não um copo qualquer, o copo cujo diâmetro equivale à circunferência da batata.

Um educando do grupo de Matemática demonstrou ao longo do processo constante insatisfação com a simplicidade do jogo proposto e sua baixa atratividade. A integração de conteúdos curriculares foi fortemente rejeitada por ele, pois em sua opinião seria impossível fazer um jogo divertido envolvendo Matemática. Em suas palavras: "o jogo vai ser chato [...] é por isso que não se faz jogo para matemática, não tem como o jogador dar pausa e ir calcular". Entretanto, em colaboração com o expert em Computação, esse mesmo educando propôs uma fase inspirada no jogo Asteroids, em que os meteoros seriam formas geométricas (inicialmente um octógono que iria se quebrando a cada tiro acertado até se tornar vários retângulos). Posteriormente, o expert em Matemática sugeriu que os meteoros fossem poliedros de Platão (Figura 2, à direita), um conceito desconhecido para o grupo. Motivado, o educando adaptou a fase dos asteroides para contemplar esse conceito, solicitando explicações ao expert e assim caracterizando o processo de aprendizagem que é almejado no DEMULTS.

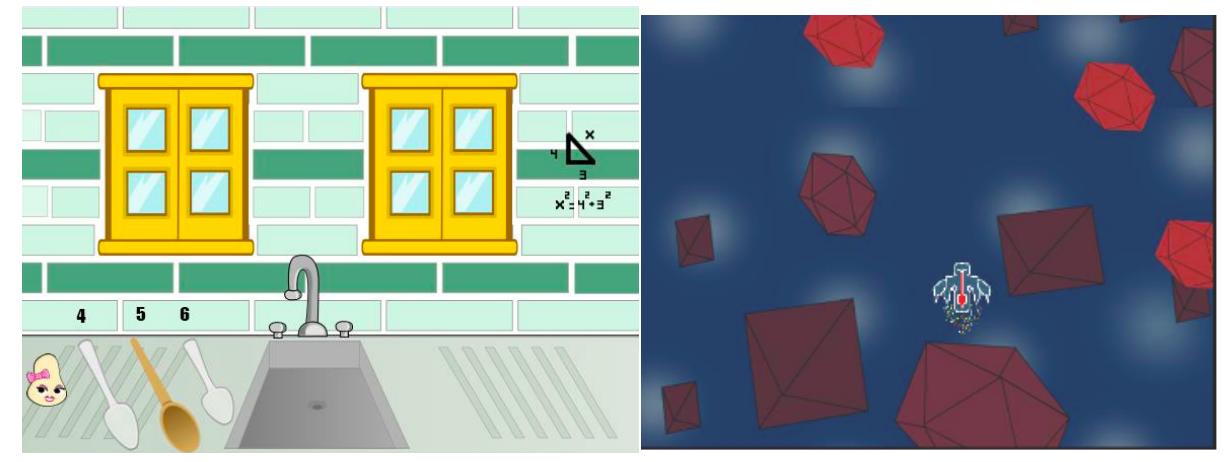

Figura 2. Cenas do jogo de Matemática

Por outro lado, o educando continuou com suas inquietações acerca da falta de diversão do jogo. Em conversa por mensagens de texto com o expert, ele disse: "temos que repensar a mecânica e a jogabilidade do game para enfim deixá-lo divertido. Porque de que adianta um bom enredo e o jogo é chato? kkk Você deve estar pensando que eu não estou ligando muito pro fato da Geometria. Sim, kkk não estou. (sic.)".

\section{Conclusões e Desdobramentos}

Pode-se inferir que os dois primeiros ciclos tiveram melhores resultados quanto à integração dos temas educacionais às narrativas dos jogos, em decorrência de: (i) maior 
autonomia dos educandos para realização de pesquisas acerca dos conteúdos curriculares, o que resultou em produtivos momentos de interação presenciais e à distância (em grupo de rede social online), nos pares educando-educando e experteducando; (ii) maior tempo de ideação para construção colaborativa dos artefatos de Game Design Document e storyboard [Morais et al. 2015], que possibilitam diversas situações de trocas discursivas; e (iii) maior integração de experts de conteúdos no processo, incluindo a professora da disciplina no segundo ciclo. O espaço simbólico que promoveu aprendizagem de conteúdos foi verificado também no terceiro ciclo a partir das trocas sociais de conhecimento promovidas pela Comunidade de Prática.

Sendo assim, aponta-se a relevância das interações dos educandos e principalmente destes com os experts, como evidência da ZDP, para promoção de aprendizagem e desenvolvimento no DEMULTS. É importante ressaltar que, algumas vezes, os educandos contrastavam a inadequação entre os significados que eles próprios produziam sobre os conceitos e o sentido que encontravam na literatura científica. Nesses casos, tais interações entre experts e educandos emergiam das necessidades dos próprios educandos em resolver um problema/conflito identificado. Isso indica um alinhamento entre o objeto da ação dos educandos com as suas necessidades, atribuindo assim um caráter legítimo à construção do conhecimento e à inserção do mesmo nas narrativas e, posteriormente, nas interfaces dos jogos.

Outro dilema presente nos três ciclos refere-se à inserção de conteúdos curriculares em um jogo digital, e tal inserção não comprometer a ludicidade e diversão do jogo. Pode-se atentar que as regularidades dessas discussões nas CP do DEMULTS realçam a apropriação de formações discursivas que podem ser encontradas também em práticas sociais de desenvolvimento de software educativos, em contextos não escolares ou mesmo profissionais de resolução de problemas. Nesse sentido, a aprendizagem de conteúdos curriculares esteve vinculada às condições da atividade de desenvolvimento de um jogo digital e, portanto, promoveu trocas discursivas sobre programação e design.

Em relação aos ciclos apresentados neste trabalho, as pesquisas do DEMULTS avançam no sentido de compreender aspectos do processo de desenvolvimento de jogos digitais educacionais para aprendizagem de conteúdos. Um possível desdobramento do DEMULTS envolve estendê-lo para escolas em contextos rurais, em que pese as particularidades da educação do campo (Ciclo 4 - DEMULTS-Campo).

\section{Referências}

Bødker, S., Grønbæk, K., Kyng, M. (1995) "Cooperative design: techniques and experiences from the Scandinavian scene". In: Readings in Human-Computer Interaction: Toward the Year 2000. Morgan-Kaufmann.

Capezzera D. e Peres, F. (2014) "Interação, Mediação e Desenvolvimento de Games Educacionais: Uma análise dos Processos de Ensino-Aprendizagem". Em: Abranches, A. et al. (Orgs.), Pesquisa Educacional e o direito à Educação: Múltiplas Abordagens. 1ed, Recife, Editora Massangana, p. 201-218.

Ehn, P., Kyng, M. (1991) Cardboard Computers: Mocking-it-up or Hands-on the Future. In: Design at work. [S.1.]: Lawrence Erlbaum Associates, Incorporated. 
VI Congresso Brasileiro de Informática na Educação (CBIE 2017)

Anais do XXIII Workshop de Informática na Escola (WIE 2017)

Halverson, R. et al. (2006) "Theorizing games in/and education". In: Proceedings of the 7th International Society of the Learning Sciences. p. 1048-1052.

Kafai, Y. B. (2006) "Playing and Making Games for Learning", In Games and Culture, v. 1 , n. 1 , pages $36-40$.

Lave, J. and Wenger, E. C. (1991) "Situated learning: Legitimate peripheral participation", Cambridge University Press.

Leontiev, A. (2004) "O Desenvolvimento do Psiquismo", São Paulo, Centauro.

Lieberman, H. et al. (2006) "End-user development: An emerging paradigm". In: End user development. Springer, p.1-8.

Maloney, J. et al. (2010) "The scratch programming language and environment." ACM Transactions on Computing Education (TOCE), vol. 10, n. 4, p. 16.

Marinho, F. C. V., Giannella, T. R. and Struchiner, M. (2011) "Estudantes do Ensino Básico Como Desenvolvedores de Jogos Digitais: Contextos Autênticos de Aprendizagem para Educação em Ciências e Matemática", Em: Atas do VIII Encontro Nacional de Pesquisa em Educação em Ciências, Campinas, São Paulo.

Morais, D. C. S., Gomes, T., Souza, A., Peres, F. (2015) "Storyboards no Desenvolvimento de Jogos Digitais Educacionais por Usuários Finais: Um Relato de Experiência". Em: Anais do Simpósio Brasileiro de Informática na Educação - SBIE 2015.

Morch, A. (1997) "Three levels of end-user tailoring: Customization, integration and extension". In: M. Kyng \& L. Mathiassen (Eds.), Computers and Context (pp. 5176). Cambridge, MA: MIT Press.

Papert, S., Harel, I. (1991) "Situating constructionism". Constructionism, v. 36, p. 1-11.

Peres, F. M. e Oliveira, G. S. (2013) "Teoria da Atividade e desenvolvimento de games educacionais: implicações das comunidades de prática para a aprendizagem em contexto escolar". Em: Hipertextus Revista Digital (UFPE), vol. 10, p.1.

Prensky, M. (2001) "Digital natives, digital immigrants", part 1. On the horizon, v. 9, n. 5, p. 1-6.

Prensky, M. (2010) "Não me atrapalhe, mãe - eu estou aprendendo". São Paulo: Phorte.

Robertson, J., Howells, C. (2008) "Computer game design: Opportunities for successful learning". In: Computers \& Education, v. 50, n. 2, p. 559-578.

Saviani, D. (2003) "Pedagogia histórico-crítica: primeiras aproximações", $8^{a}$ edição, Campinas, Autores Associados.

Vygotsky, L. S. (1991) "A formação social da mente: o desenvolvimento dos processos psicológicos superiores", São Paulo, Martins Fontes.

Wenger, E. (2000) "Communities of practice and social learning systems". Organisation, v.7, n.2, p. 225-246. 